\title{
Child sexual abuse in Nunavut linked to suicide
}

A t 10 years of age, Clyde "Aapi" Akumalik was sexually abused; that trauma was followed, about a year later, by his first suicide attempt.

Fourteen years later, Akumalik completed suicide. That devastating loss prompted his father, a city councillor, to testify during a Sept. 14-25 inquest into suicide rates in Nunavut, which are nearly ten times higher than elsewhere in Canada.

"I'm hoping our government will better think about suicide as a very important issue," says Joanasie Akumalik.

His courageous decision to testify about his son's sexual abuse and its lasting consequences exposed the dark realities underlying a crisis that has exploded beyond the fledgling territorial g overnment's ability to cope with it.

Sexual abuse during childhood is an important risk factor for suicide. In Nunavut, suicide is often related to historic trauma stemming from colonization, forced resettlement and loss of traditional roles. In addition, abuse has occurred in residential schools by some priests and teachers, a few of whom have been convicted.

Many Inuit affected by historic trauma have never healed, according to the Nunavut Suicide Prevention Strategy. The unresolved trauma has affected subsequent generations, particularly their ability to handle stress. "The symptoms of this deep-rooted trauma invariably results in negative behaviours in the form of alcohol abuse, sexual, physical, and emotional abuse, child neglect, and violent crime," states a feasibility study prepared for the Arctic Children and Youth Foundation into the need for a child advocacy centre in Nunavut.

More than half of women (52\%) and $22 \%$ of men reported severe sexual abuse in childhood, according to the Inuit Health Survey of 2007-2008. Nunavut Tunggavik Inc., the Inuit organization responsible for implementing the land claim agreement in

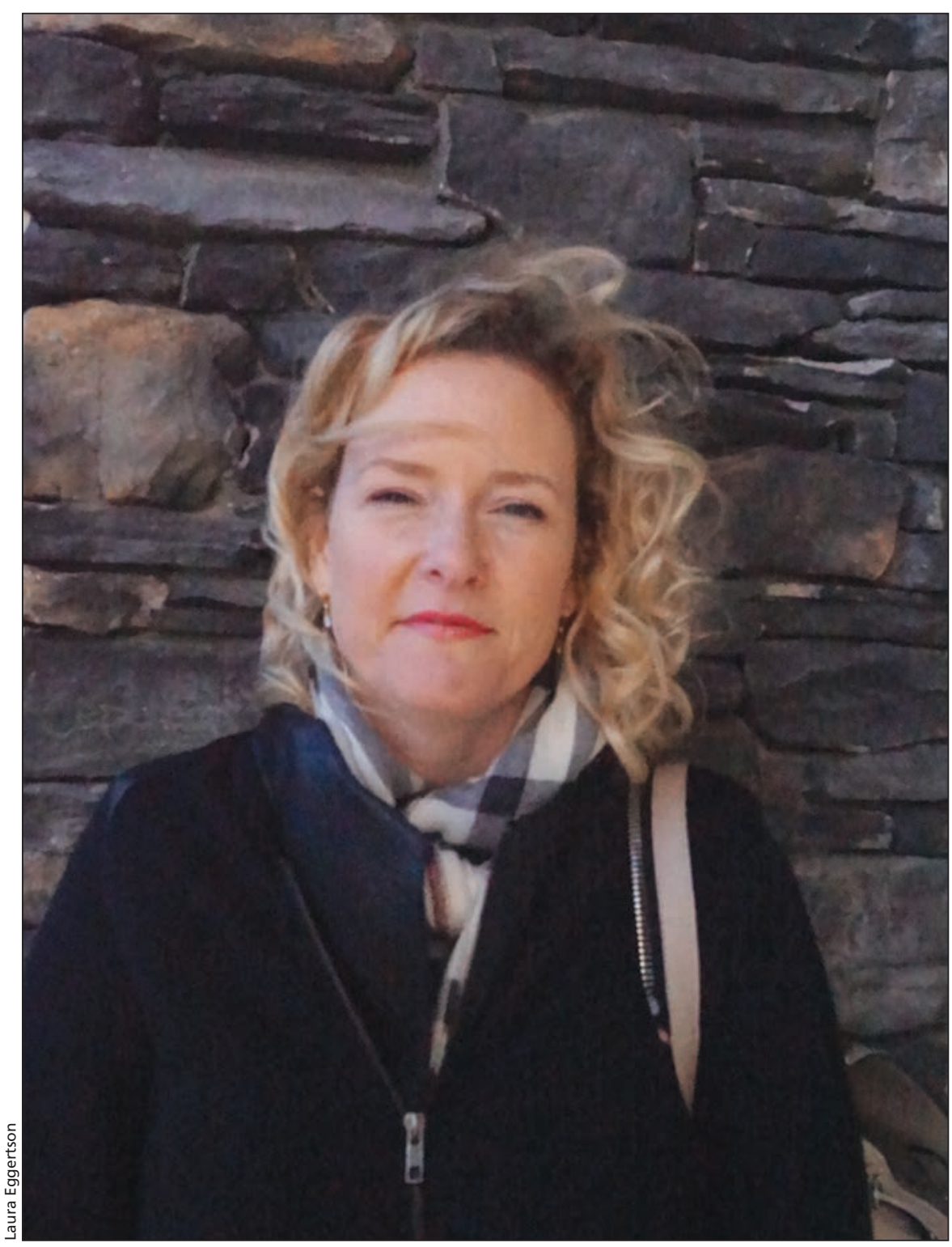

"We can't leave it up to children to protect themselves" from sexual abuse, testified psychiatrist Allison Crawford.

Nunavut, cites those statistics in a report chastising the territory for failing its children and youth.

Adults were surveyed, but children are also being sexually abused. Cases of children with sexually transmitted infections and other evidence of sexual abuse come to the regular attention of psychiatric nurses and psychiatrists, says Dr. Allison Crawford, director of the Northern Psychiatric Outreach Pro- gram for the Centre for Addiction and Mental Health in Toronto.

"The degree of childhood abuse is something that I think is talked about even less than suicide," she testified at the inquest. "It's still present and prevalent in communities."

On average, offenders in Nunavut are charged with sexual violations against children and youth at 10 times the national rate, according to statistics 
compiled for the Child Advocacy Centre Feasibility Study.

"We have a new case that's come to the attention of mental health at least monthly, and sometimes more frequently," Crawford said in an interview. "Social services do become involved automatically, and often the RCMP will become involved. But often the outcome - there are very few consequences."

Most children in Nunavut are well cared for, Crawford emphasized. But the territory must invest more in child protection, on par with suicide prevention, she said. She also urged public figures to acknowledge not only suicide but its connections to sexual abuse and other childhood trauma. "We can't leave it up to children to protect themselves."

Akumalik's earlier suicide attempt is focusing the jury's attention on the critical importance of tracking, following and supporting those in distress.

"One of the easiest ways of saving lives and preventing suicides is to systematically ... follow up after anyone attempts suicide," testified Brian Mishara, a psychology professor and director of the Centre for Research and Intervention on Suicide and Euthanasia at the Université du Quebec à Montréal.

Regularly telephoning or texting people who have attempted suicide to let them know someone cares has proven to be effective prevention, Mishara testified. In Montréal, for example, hospitals have an agreement with the suicide prevention hotline to follow up with patients who have left hospital.

This public health model has also been successful in White Mountain Apache territory, testified Crawford. After a spike of 11 suicides in 2001, many involving youth, the tribal council worked with Johns Hopkins University to build a surveillance system. First responders enter data about people after suicide attempts or incidents of suicidal ideation and self-harm. Community members follow up by phone and home visits.

When young Akumalik disclosed the sexual abuse, no one reported it. When he tried to hang himself, his uncle cut him down in time to save his life. No health professionals were involved.

"I think it would have opened doors for him if somebody was there to follow up, or if somebody had reported it," his father says. "I think that would have changed the course of his life."

Collecting and releasing suicide attempt data was one of Nunavut's commitments, in partnership with the RCMP, under its 2011 action plan. The government was to develop "protocols and methods" to record suicide attempts - a commitment the Nunavut Depart- ment of Health failed to carry out, Jack Hicks, a researcher and expert witness, testified at the inquest.

"In terms of data collection, it's a huge challenge," Lynn Ryan MacKenzie, the government's executive director of mental health and addictions, told the inquest. "We would have to do a feasibility study."

Although the RCMP gathers raw data about suicide attempts, it does not have the staff to collect and analyze data, says a spokesperson. In 2014, for example, officers in 15 of the territory's 25 communities responded to 79 attempts, according to RCMP data provided to Hicks. That's "a fraction of the total number," says Hicks; it does not encompass hospital data or attempts community health workers or counsellors hear about.

All people who attempt suicide should be contacted regularly for years after their initial attempt, Mishara said in his recommendations to the inquest. "The best follow-up does not wait for attempters to ask for help or require their permission. When people repeatedly and persistently contact people who have attempted suicide on a regular basis, expressing their sincere concern for the person's well-being, lives are saved." Laura Eggertson, Iqaluit, Nunavut

CMAJ 2015. DOI:10.1503/cmaj.109-5162 